\title{
Ball milling as an effective route for the preparation of doped bornite: synthesis, stability and thermoelectric properties
}

Article

Accepted Version

Guélou, G., Powell, A. V. and Vaqueiro, P. (2015) Ball milling as an effective route for the preparation of doped bornite: synthesis, stability and thermoelectric properties. Journal of Materials Chemistry C, 3 (40). pp. 10624-10629. ISSN 20507526 doi: https://doi.org/10.1039/C5TC01704A Available at https://centaur.reading.ac.uk/42437/

It is advisable to refer to the publisher's version if you intend to cite from the work. See Guidance on citing.

To link to this article DOI: http://dx.doi.org/10.1039/C5TC01704A

Publisher: Royal Society of Chemistry

All outputs in CentAUR are protected by Intellectual Property Rights law, including copyright law. Copyright and IPR is retained by the creators or other copyright holders. Terms and conditions for use of this material are defined in the End User Agreement.

www.reading.ac.uk/centaur 
Central Archive at the University of Reading

Reading's research outputs online 


\title{
Journal of Materials Chemistry C
}

\section{ARTICLE}

\section{Ball milling as an effective route for the preparation of doped bornite: synthesis, stability and thermoelectric properties}

Received 00th January 20xx Accepted 00th January 20xx

DOI: $10.1039 / x 0 x \times 00000 x$

www.rsc.org/

\author{
G. Guélou, A. V. Powell and P. Vaqueiro*
}

\begin{abstract}
Bornite, $\mathrm{Cu}_{5} \mathrm{FeS}_{4}$, is a naturally-occuring mineral with an ultralow thermal conductivity and potential for thermoelectric power generation. We describe here a new, easy and scalable route to synthesise bornite, together with the thermoelectric behaviour of manganese-substituted derivatives, $\mathrm{Cu}_{5} \mathrm{Fe}_{1-\mathrm{x}} \mathrm{Mn}_{\mathrm{x}} \mathrm{S}_{4}(0 \leq \mathrm{x} \leq 0.10)$. The electrical and thermal transport properties of $\mathrm{Cu}_{5} \mathrm{Fe}_{1-x} \mathrm{Mn}_{\mathrm{x}} \mathrm{S}_{4}(0 \leq \mathrm{x} \leq 0.10)$, which are $\mathrm{p}$-type semiconductors, were measured from room temperature to $573 \mathrm{~K}$. The stability of bornite was investigated by thermogravimetric analysis under inert and oxidising atmospheres. Repeated measurements of the electrical transport properties confirm that bornite is stable up to $580 \mathrm{~K}$ under an inert atmosphere, while heating to $890 \mathrm{~K}$ results in rapid degradation. Ball milling leads to a substantial improvement in the thermoelectric figure of merit of unsusbtituted bornite ( $\mathrm{ZT}=0.55$ at $543 \mathrm{~K}$ ), when compared to bornite prepared by conventional high-temperature synthesis ( $\mathrm{ZT}<0.3$ at $543 \mathrm{~K}$ ). Manganese-substituted samples have a ZT comparable to that of unsubstituted bornite.
\end{abstract}

\section{Introduction}

Thermoelectric power generation has the potential to achieve significant energy savings through the conversion of waste heat, generated in many industrial processes, into electrical energy. Current commercial devices mainly contain doped derivatives of $\mathrm{Bi}_{2} \mathrm{Te}_{3}$, with a figure of merit $\left(\mathrm{ZT}=\mathrm{S}^{2} \sigma \mathrm{T} / \kappa\right.$, where $T$ is the temperature, $S$ is the Seebeck coefficient, $\sigma$ the electrical conductivity and $\mathrm{K}$ the thermal conductivity) approaching unity at $380 \mathrm{~K}^{1}$ The high cost of existing thermoelectric devices, which is linked to the scarcity of tellurium, combined with their relatively low conversion efficiency, which is related to $\mathrm{ZT}$, confine this technology to specialised applications. To enable large-scale implementation of thermoelectric power generation, and hence contribute towards a reduction in greenhouse gas emissions, new thermoelectric materials composed of earth-abundant, nontoxic elements, are urgently needed. In this context, it is surprising that naturally occurring minerals have been overlooked as candidate thermoelectric materials until fairly recently. Given that synthetic sulfides, such as n-type $\mathrm{Ti}_{1+x} \mathrm{~S}_{2}$ $(\mathrm{ZT}=0.48$ at $700 \mathrm{~K}$ for $\mathrm{x}=0.025),{ }^{2}$ can exhibit large power factors, $S^{2} \sigma$, sulfominerals containing abundant elements are particularly attractive candidates for investigation. Current efforts have focused on p-type sulfides with the structure of

\footnotetext{
* Department of Chemistry, University of Reading, Whiteknights, RG6 6AD, UK; Email:p.vaqueiro@reading.ac.uk

† Electronic Supplementary Information (ESI) available: Powder X-ray diffraction data, elemental maps determined by EDX, repeated electrical transport property measurements, thermal diffusivity and TGA/DSC data. See DOI: $10.1039 / \mathrm{x} 0 \times x \times 0000 x$
}

the mineral tetrahedrite, ${ }^{3,4,5,6,7}$ and it has already been shown that a zinc and nickel-substituted tetrahedrite, $\mathrm{Cu}_{10.5} \mathrm{NiZn}_{0.5} \mathrm{Sb}_{4} \mathrm{~S}_{13}$, reaches an impressive value of $\mathrm{ZT}=1.03$ at $723 \mathrm{~K}^{5}$ More recently, the mineral bornite has been identified as a potential candidate for thermoelectric power generation. ${ }^{8}$ Bornite is a copper iron sulfide with stoichiometry $\mathrm{Cu}_{5} \mathrm{Fe}_{2} \mathrm{~S}_{4}$, where $\square$ represents a vacancy. This material adopts an antifluorite-related structure that undergoes complex cation order-disorder phase transitions over the temperature range $473 \leq \mathrm{T} / \mathrm{K} \leq 543 .{ }^{9,10,11}$ Above $543 \mathrm{~K}$, vacancies are completely disordered, and the material adopts an antifluorite-type structure (space group $F m \overline{3} m, a \approx 5.5 \AA$, denoted as $1 a$ ). ${ }^{10}$ At room temperature, long-range ordering and clustering of vacancies results in an orthorhombic (pseudo-tetragonal) structure $(2 a \times 4 a \times 2 a$, space group $\mathrm{Pbca})$ consisting of antifluorite and sphalerite subcells (Fig. 1), ${ }^{12}$ although a HRTEM study suggests that at room temperature, $1 a, 2 a, 4 a$ and $6 a$ superstructure domains coexist. ${ }^{13}$ At intermediate temperatures $(473<\mathrm{T} / \mathrm{K}<543)$, a cubic $2 a \times 2 a \times 2 a$ supercell (denoted as $2 a$ ) is found. ${ }^{14,15}$ The structure of the intermediate

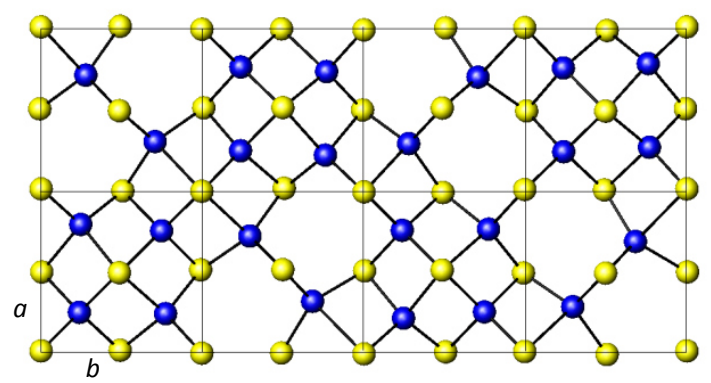

Fig. 1 View of the vacancy ordering in the low-temperature phase of $\mathrm{Cu}_{5} \mathrm{FeS}_{4}$, illustrating the alternating sphalerite and antifluorite subcells. $\mathrm{Key}$ : $\mathrm{Cu} / \mathrm{Fe}$, blue circles; $\mathrm{S}$, yellow circles. 
$2 a$ phase consists of alternating Fe-containing and Fe-free subcells, ${ }^{14,15}$ while in the high-temperature $1 a$ phase Fe and $\mathrm{Cu}$ are statistically distributed over the available tetrahedral sites. ${ }^{10}$ Changes in the temperatures at which these two phase transitions occur have been related to the iron content and the Cu:Fe ratio. ${ }^{16}$

Bornite has also attracted interest as a potential photovoltaic material, due to its band gap of approximately 1 $\mathrm{eV},{ }^{17,18}$ and this has led to investigations of its solution-based synthesis, using oleic acid or ethylene glycol as solvents under reflux. ${ }^{18,19}$ However, the established route for the preparation of synthetic bornite involves high-temperature solid-state reactions for several days using evacuated and sealed silica ampoules. ${ }^{8,10,16}$ Here, we present the first report of the synthesis of bornite by ball milling, which circumvents the formation of impurities such as $\mathrm{Cu}_{2-\mathrm{x}} \mathrm{S}$ often found in samples prepared by high-temperature reactions, and reduces the synthesis time. Although stoichiometric bornite has an extremely low thermal conductivity, its electrical conductivity is also low, owing to its low charge carrier density. ${ }^{8}$ In seeking to improve the electrical transport properties of bornite, we have explored doping of $\mathrm{Cu}_{5} \mathrm{FeS}_{4}$ by partial substitution of the trivalent iron with divalent transition metals with similar ionic radii, and found significant levels of incorporation of manganese. The investigation of the thermoelectric properties of manganese-doped bornite, $\mathrm{Cu}_{5} \mathrm{Fe}_{1-\mathrm{x}} \mathrm{Mn}_{\mathrm{x}} \mathrm{S}_{4}$ is also presented here.

\section{Experimental}

Samples with composition $\mathrm{Cu}_{5} \mathrm{Fe}_{1-\mathrm{x}} \mathrm{Mn}_{\mathrm{x}} \mathrm{S}_{4}(0 \leq \mathrm{x} \leq 0.1)$ were synthesised by ball milling $\mathrm{Cu}$ (Sigma Aldrich, 99.5\%), Fe (Sigma Aldrich, 99.9\%), Mn (Alfa Aesar, 99.95\%) and S (Sigma Aldrich, flakes, 99.99\%). Stoichiometric amounts of each element were ground and then placed in a $25 \mathrm{ml}$ stainless-steel jar together with $6 \mathrm{~mm}$ stainless-steel balls, under an argon atmosphere. The weight ratio of powder to balls was 3:7. Two successive millings were carried out using a Retsch Planetary Ball Mill PM 100, at $500 \mathrm{rpm}$ with $5 \mathrm{~min}$ interval steps, with a change of direction, for $20 \mathrm{~h}$ each. The resulting powder was consolidated using a hot press, at $823 \mathrm{~K}$ for $30 \mathrm{~min}$, under a pressure of $110 \mathrm{MPa}$. A graphite mould with tungsten carbide dies was used, and hot pressing was carried out under a nitrogen flow to prevent oxidation. The densities of the consolidated pellets were measured using an Archimedes balance ADAM PW184. All samples were found to have densities close to the crystallographic value (>99\%), ranging between $5.00 \mathrm{~g} . \mathrm{cm}^{-3}$ and $5.06 \mathrm{~g} . \mathrm{cm}^{-3}$.

Powder X-ray diffraction data were collected using a Bruker D8 Advance Powder X-ray diffractometer, operating with Ge monochromated CuK $_{\alpha 1}$ radiation $(\lambda=1.54046 \AA)$ and fitted with a LynxEye detector. Data were collected over the angular range $5 \leq 2 \theta /{ }^{\circ} \leq 75$ for a period of 6 hours. Le Bail refinements on hot-pressed samples have been performed using the GSAS package. $^{20}$ Simultaneous thermogravimetric (TGA) and heat flow (DSC) data were collected using a TA-Q600SDT TGA instrument over the temperature range $300 \leq \mathrm{T} / \mathrm{K} \leq 973$. Data were collected under a flowing $\mathrm{N}_{2}$ atmosphere and under flowing air. EDX analysis was carried out on an FEI Quanta FEG 600 Environmental Scanning Electron Microscope (ESEM) with a high voltage of $20 \mathrm{kV}$ in high-vacuum mode. Measurements were carried out on hot-pressed pellets.

Prior to physical property measurements, the consolidated pellets were polished using a MTI EQ-Unipol-300 grinder/polisher. The polished disks have a diameter of $c a$. $12.7 \mathrm{~mm}$ and a thickness of $c a .2 \mathrm{~mm}$ with less than $0.05 \mathrm{~mm}$ variation across the whole surface. The temperature dependence of the electrical resistivity ( $\rho$ ) and Seebeck coefficient (S) was measured simultaneously on the polished disks using a Linseis LSR-3 instrument, under a partial pressure of $\mathrm{He}$, and over the temperature range $310 \leq \mathrm{T} / \mathrm{K} \leq 580$. The electrical resistivity was measured with the four-point $D C$ method using a current of $50 \mathrm{~mA}$ between the terminal $\mathrm{Pt}$ electrodes and with the axial thermocouple probes separated by a distance of $8.0 \mathrm{~mm}$. For Seebeck coefficient measurements, a constant $50 \mathrm{~K}$ temperature gradient was applied.

Thermal diffusivity was measured over the temperature range $303 \leq \mathrm{T} / \mathrm{K} \leq 573$ using a Netzsch LFA 447 NanoFlash instrument. Cowan's model with a pulse correction was applied. ${ }^{21}$ The Dulong-Petit heat capacity $\left(C_{p}=0.497 \mathrm{~J} \mathrm{~K}^{-1} \mathrm{~g}^{-1}\right.$ for $\mathrm{Cu}_{5} \mathrm{FeS}_{4}$ ) was used to estimate the thermal conductivity.

\section{Results and discussion}

Ball milling of a mixture with stoichiometry $\mathrm{Cu}_{5} \mathrm{FeS}_{4}$ produces a fine black powder, and powder X-ray diffraction data collected on this material (Fig. 2a) are consistent with the presence of poorly crystalline cubic bornite, together with a small amount of unreacted iron. Following hot pressing at $823 \mathrm{~K}$, the sample consists of crystalline bornite, adopting the low-temperature structure (Fig. 2b). Powder diffraction patterns for the ballmilled powder (Fig. 2a) and the hot-pressed pellet (Fig. 2b) confirm the absence of impurities such as chalcopyrite, pyrrhotite or pyrite. A Le Bail refinement using data collected on the hot-pressed material resulted in lattice parameters ( $a=$ 10.9484(3) Å, $b=21.8647(8) \AA$ and $c=10.9484(3) \AA$ ) which are consistent with previous reports for the low-temperature

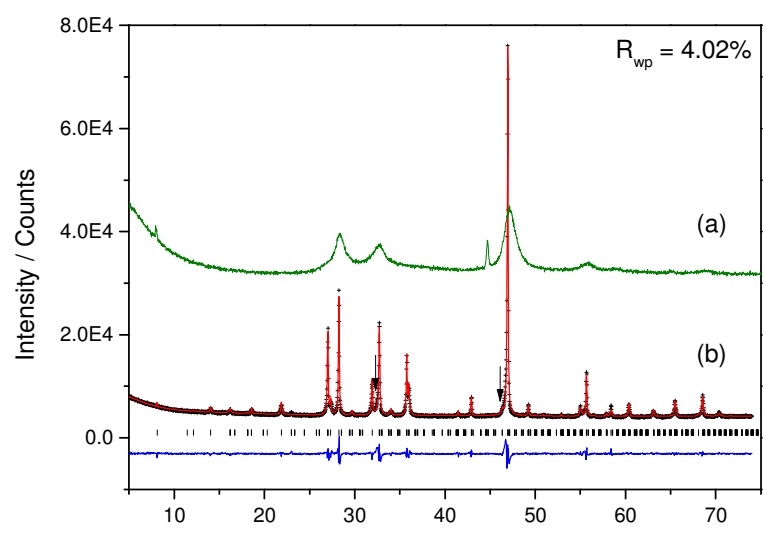

Fig. 2 (a) Powder X-ray diffraction pattern of ball-milled $\mathrm{Cu}_{5} \mathrm{FeS}_{4}$. (b) Le Bail refinement using $X$-ray diffraction data collected on the hot-pressed bornite pelfet, including the observed (black crosses), calculated (red line) and
difference (lower blue line) profiles. Reflection positions for the orthorhombic $2 a \times 4 a \times 2 a$ phase are shown as markers. Arrows indicate orthorhombic $2 a \times 4 a \times 2 a$ phase are shown as mark
peak shoulders that can be indexed with a $1 a$ unit cell. 


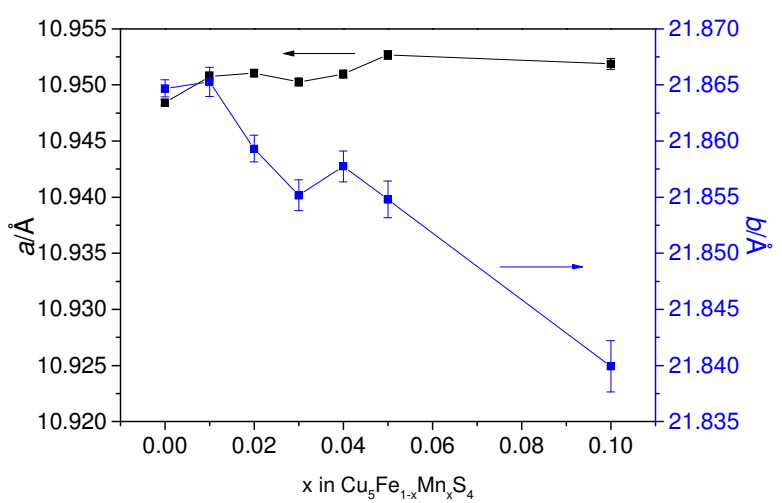

Fig. 3 Lattice parameters as a function of manganese content. Error bars are shown.

Table 1. Composition of the $\mathrm{Cu}_{5} \mathrm{Fe}_{1-\mathrm{x}} \mathrm{Mn}_{\mathrm{x}} \mathrm{S}_{4}$ samples determined by EDX analysis. Standard deviations are given within brackets.

\begin{tabular}{|c|c|c|c|}
\hline $\mathbf{x}$ & Experimental composition & $\mathbf{x}$ & Experimental composition \\
\hline 0 & $\mathrm{Cu}_{4.89(2)} \mathrm{Fe}_{1.00(1)} \mathrm{S}_{4.11(3)}$ & 0.04 & $\mathrm{Cu}_{4.91(3)} \mathrm{Fe}_{0.97(1)} \mathrm{Mn}_{0.042(4)} \mathrm{S}_{4.08(3)}$ \\
\hline 0.01 & $\mathrm{Cu}_{4.91(3)} \mathrm{Fe}_{1.00(1)} \mathrm{Mn}_{0.016(4)} \mathrm{S}_{4.08(3)}$ & 0.05 & $\mathrm{Cu}_{4.93(3)} \mathrm{Fe}_{0.94(1)} \mathrm{Mn}_{0.044(5)} \mathrm{S}_{4.09(3)}$ \\
\hline 0.02 & $\mathrm{Cu}_{4.87(3)} \mathrm{Fe}_{0.98(1)} \mathrm{Mn}_{0.019(5)} \mathrm{S}_{4.13(4)}$ & 0.10 & $\mathrm{Cu}_{4.88(3)} \mathrm{Fe}_{0.91(1)} \mathrm{Mn}_{0.107(5)} \mathrm{S}_{4.10(3)}$ \\
\hline 0.03 & $\mathrm{Cu}_{4.90(3)} \mathrm{Fe}_{0.97(1)} \mathrm{Mn}_{0.042(4)} \mathrm{S}_{4.09(3)}$ & - & - \\
\hline
\end{tabular}

orthorhombic phase. ${ }^{12}$ Traces of a cubic phase, which can be indexed with a lattice parameter $a \approx 5.50 \AA$, remain in the hotpressed material, as highlighted by arrows in Fig. 2(b). It has been reported that quenching bornite from elevated temperatures results in the isolation of the intermediate $2 a$ phase. ${ }^{10}$ After several weeks at room temperature, bornite converts to the thermodynamically-favoured orthorhombic polymorph. ${ }^{10}$ In our hot-pressed samples, only traces of a cubic phase are present immediately after preparation, and by powder diffraction we cannot determine unequivocally whether this phase is the high-temperature $1 a$ or the intermediate $2 a$ cubic phase. Powder diffraction patterns (ESI, Fig. S1) for samples containing manganese, $\mathrm{Cu}_{5} \mathrm{Fe}_{1-x} \mathrm{Mn}_{x} \mathrm{~S}_{4}$, are similar to those of pure bornite up to $x=0.05$. For $x=0.1, a$ trace amount of alabandite (MnS) can be detected, suggesting that the solubility limit of $\mathrm{Mn}$ in bornite is $\mathrm{x} \approx 0.1$. Whilst the $a$ and $c$ lattice parameters of the orthorhombic phase change little with manganese content, the $b$ parameter changes quite markedly (Fig 3). In particular, $b$ decreases with increasing $x$, but instead of a linear dependence, exhibiting a weak anomaly over the compositional range $0.01 \leq \mathrm{x} \leq 0.04$. Compositions determined by EDX analysis (Table 1 ) on consolidated ingots are in agreement with the initial composition of the reaction mixtures, suggesting that no significant loss of elements has taken place during the synthesis and consolidation process. Elemental maps (ESI, Fig. S2) indicate a homogeneous distribution of constituent elements over the ingot.

Thermogravimetric data (ESI, Fig. S3) collected under a flowing $\mathrm{N}_{2}$ atmosphere show that $\mathrm{Cu}_{5} \mathrm{FeS}_{4}$ starts to lose weight above ca. $600 \mathrm{~K}$. This is indicative of sulphur loss above this temperature, and could result in exsolution of chalcopyrite $\left(\mathrm{CuFeS}_{2}\right)$ or $\mathrm{Cu}_{2-\mathrm{x}} \mathrm{S}$ on cooling, a process which has been reported to occur in non-stoichiometric bornites when cooling from high temperatures. ${ }^{22}$ Under an air atmosphere, the onset of oxidation occurs at ca. $673 \mathrm{~K}$. DSC measurements under $\mathrm{N}_{2}$ (ESI, Fig. S3) show two transitions at ca. 460 and $530 \mathrm{~K}$. The transitions observed in our DSC measurements are consistent with those found in previous reports, ${ }^{11,16}$ including a study in which a combination of powder neutron diffraction and DSC was used, ${ }^{11}$ and correspond to the transition from lowtemperature orthorhombic $(2 a \times 4 a \times 2 a \text { supercell })^{12}$ to intermediate bornite $(2 a \text { supercell })^{14}$ at $460 \mathrm{~K}$, and from intermediate to high-temperature cubic bornite ( $1 a$ unit cell $)^{10}$ at $530 \mathrm{~K}$.

Taking into account the temperature at which sulphur loss starts to occur under a flowing inert atmosphere, the electrical transport properties of manganese-substituted bornites were measured only to $580 \mathrm{~K}$. This resulted in values that remain unchanged above the first phase transition when measuring the same ingot repeatedly over a period of several weeks, as illustrated in Fig. S4 (ESI). The power factor remains unchanged (within experimental error) when repeating measurements up to $580 \mathrm{~K}$ over a period of 10 weeks (Fig S4). By contrast, when measurements are extended to a temperature of $890 \mathrm{~K}$, exsolution of $\mathrm{Cu}_{2-x} \mathrm{~S}$ occurs (as confirmed by powder X-ray diffraction, Fig S5), the Seebeck coefficient becomes negative and the resistivity increases markedly, as illustrated in Fig. 4. This suggests that a protective coating to avoid sulfur loss may be required to ensure material stability at operating temperatures above $580 \mathrm{~K}$.

The temperature dependence of the electrical transport properties measured up to $580 \mathrm{~K}$ for $\mathrm{Cu}_{5} \mathrm{Fe}_{1-x} \mathrm{Mn}_{x} \mathrm{~S}_{4}$ is shown in Fig. 5, while the evolution of $\rho$ and $S$ as a function of $x$ at three temperatures is illustrated in Fig. 6 . These data indicate that all samples behave as semiconductors with a large $p$-type Seebeck coefficient, and exhibit an anomaly at the temperature at which the transition from the orthorhombic to the intermediate cubic phase occurs. The electrical resistivity

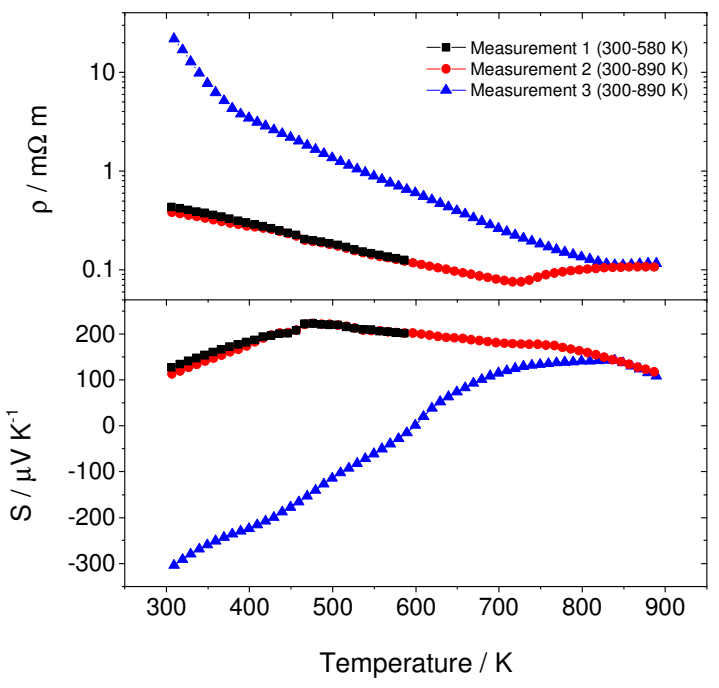

Fig. 4 Repeated measurements of the temperature dependence of the electrical resistivity (top) and the Seebeck coefficient (bottom) for one ingot of $\mathrm{Cu}_{5} \mathrm{FeS}_{4}$. $\mathrm{F}$. to $890 \mathrm{~K}$. 


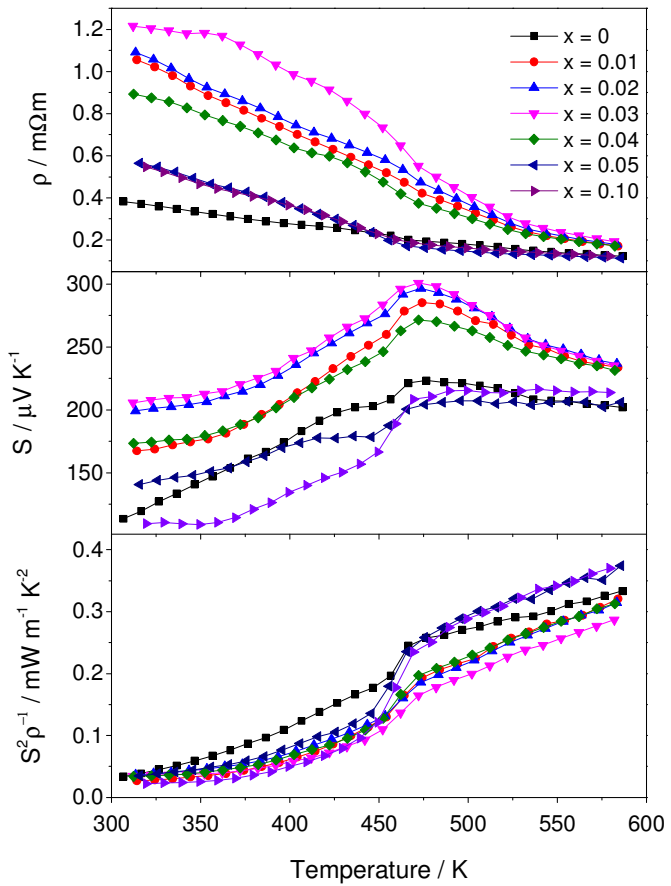

Fig. 5 Temperature dependence of the electrical resistivity (top), the Seebeck coefficient (middle) and the resulting power factor (bottom) for $\mathrm{Cu}_{5} \mathrm{Fe}_{1-x} \mathrm{Mn}_{x} \mathrm{~S}_{4}$ over the temperature range $300 \leq \mathrm{T} / \mathrm{K} \leq 580$.

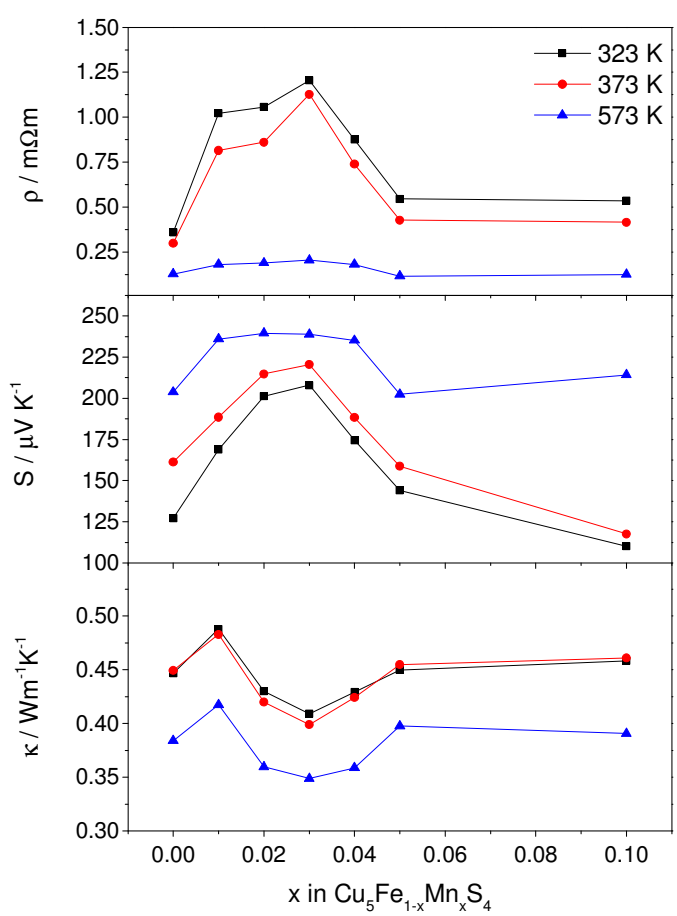

Fig. 6 Transport properties of $\mathrm{Cu}_{5} \mathrm{Fe}_{1-x} \mathrm{Mn}_{x} \mathrm{~S}_{4}$ at 323,373 and $573 \mathrm{~K}$, as a function of the manganese substitution level: electrical resistivity (top) Seebeck coefficient (middle) and thermal conductivity (bottom).

of $\mathrm{Cu}_{5} \mathrm{FeS}_{4}$ follows an Arrhenius law over the temperature ranges $300 \leq \mathrm{T} / \mathrm{K} \leq 416$ (low-temperature phase) and $520 \leq \mathrm{T}$ / $\mathrm{K} \leq 580$ (high-temperature phase). The activation energies determined from an Arrhenius plot are similar to those reported previously for stoichiometric bornite $(c a .0 .1 \mathrm{eV}) .^{8}$
However, given that diffuse reflectance measurements indicate that the optical band gap of bornite is of the order of $1 \mathrm{eV},{ }^{17,18}$ we attribute these activation energies to the promotion of extrinsic (rather than intrinsic) charge carriers. The Seebeck coefficient reaches a maximum at $c a .470 \mathrm{~K}$, the temperature at which the first phase transition occurs. The highest Seebeck coefficient is found for $x=0.03$, with a value of $300 \mu \mathrm{V} \mathrm{K}^{-1}$, significantly larger than the value of $223 \mu \mathrm{V} \mathrm{K}$ found for $\mathrm{Cu}_{5} \mathrm{FeS}_{4}$. It has been established that the oxidation state of iron in bornite is $\mathrm{Fe}(\mathrm{III}),{ }^{23}$ hence substitution of Fe(III) with $\mathrm{Mn}$ (II) should result in an increase in the hole concentration. For the ordered orthorhombic phase, low levels of manganese doping lead to an increase in the electrical resistivity as well as in the Seebeck coefficient, while at doping levels above $x=0.03$, the resistivity and Seebeck coefficient begin to decrease. The dependence of the electrical transport properties on manganese content appears to show a similar anomaly to that observed for the lattice parameters (Fig. 3). This suggests manganese may be occupying different crystallographic sites depending on the substitution levels. Given that iron and copper in bornite are both located in similar tetrahedral sites, and that the structure contains additional vacant tetrahedral sites, a structural study by powder neutron diffraction in order to establish the location of the manganese atoms, combined with XANES to ascertain the oxidation states of the metals in the doped samples, would be useful to understand the observed trend. In the temperature region (above $530 \mathrm{~K}$ ) where the disordered $1 a$ cubic phase exist, the maximum in $\rho$ and $\mathrm{S}$ is substantially reduced (Fig. 6), suggesting that vacancy disordering has a significant effect on the band structure of bornite. This is supported by the marked change in the magnitude of the optical band gap between the low-temperature $(0.86 \mathrm{eV})$ and the high-temperature $(1.25 \mathrm{eV})$ phases. ${ }^{18}$ The power factor, which is $0.33 \mathrm{~mW} \mathrm{~m}^{-1} \mathrm{~K}^{-2}$ at $580 \mathrm{~K}$ for $x=0$, changes slightly across the series, with the highest

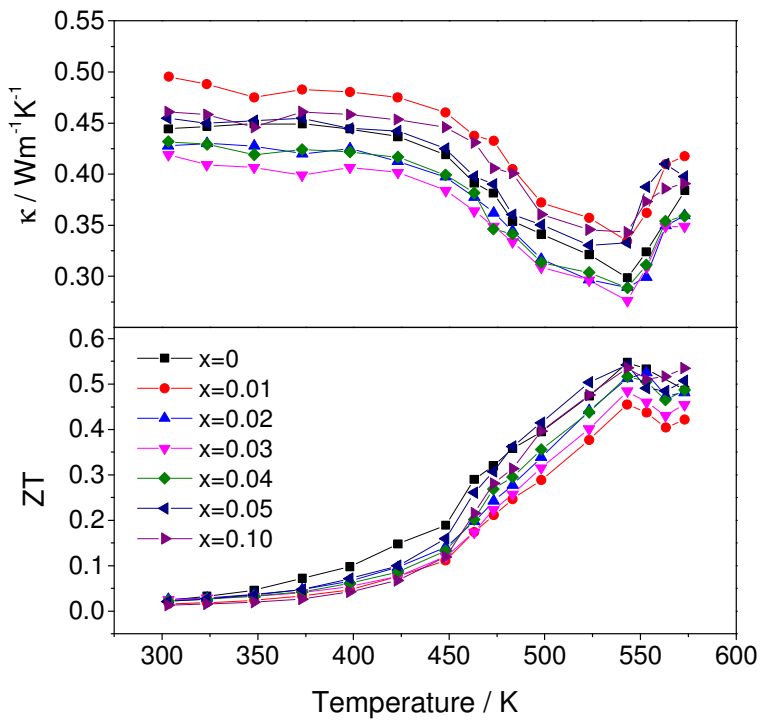

Fig. 7 Temperature dependence of the thermal conductivity (top) and ZT (bottom) for $\mathrm{Cu}_{5} \mathrm{Fe}_{1-x} \mathrm{Mn}_{\mathrm{x}} \mathrm{S}_{4}$. 
value of $0.37 \mathrm{~mW} \mathrm{~m}^{-1} \mathrm{~K}^{-2}$ reached for $\mathrm{x}=0.10$ at the same temperature.

The temperature dependence of the total thermal conductivity is given in Fig. 7, with the evolution as a function of the manganese content at different temperatures shown at the bottom of Fig. 6. At the two transition temperatures, changes in the slope of the thermal diffusivity (ESI, Fig. S6) are responsible for the anomalies observed in the thermal conductivity. Phase transitions with a marked effect on the thermoelectric performance have been observed in other thermoelectric materials, such as the structurally-related $\mathrm{Cu}_{2}$ ${ }_{x} \mathrm{Se}$ and $\mathrm{SnSe}^{24,25}$ both of which exhibit very low thermal conductivities. The thermal conductivity of the Mn-substituted bornite series is extremely low, and reaches a minimum value for $x=0.03$. For this composition, it takes values of the order $0.4 \mathrm{~W} \mathrm{~m}^{-1} \mathrm{~K}^{-1}$, which is about $70 \%$ of the thermal conductivity of water. $^{26}$ For the high-temperature cubic phase, the extremely low thermal conductivity could be attributed to the complete disorder of the cation sublattice, which consists of copper and iron cations, as well as vacancies. The magnitude of the thermal conductivity of bornite is comparable to that found for the "phonon-liquid electron-crystal" (PLEC) $\mathrm{Cu}_{2-x} \mathrm{~S}^{27}$ Given the close structural relationship between the hightemperature phase of $\mathrm{Cu}_{5} \mathrm{FeS}_{4}$ and $\mathrm{Cu}_{2-\mathrm{S}} \mathrm{S}$, it could be argued that copper ion mobility is responsible for the low thermal conductivity of bornite. However, Qiu and coworkers have reported electrical resistance data that suggests that copper migration in bornite is largely supressed, due to the presence of less mobile iron ions which have a pinning effect. ${ }^{8}$ Surprisingly, the magnitude of the thermal conductivity for the low-temperature ordered phase is comparable to those of the intermediate and high-temperature phases. Although in lowtemperature bornite long-range ordering of vacancies occurs, this phase appears to have a complex microstructure, which may consist of domains of different superstructures, ${ }^{13}$ or twinning domains. ${ }^{10,12}$ This complex microstructure could be responsible for the ultralow thermal conductivity. The initial drop in thermal conductivity with manganese substitution, up to $x=0.03$, may arise as a consequence of the additional mass fluctuation created by the substitution of iron by lighter manganese. At higher substitution levels, above $x=0.04$, the electronic component of the thermal conductivity, determined using the Wiedemann-Franz law (ESI, Fig. S7) increases, but this alone cannot explain the overall trend, which may be related to changes in the location of the manganese dopant in the crystal structure as $x$ increases.

As a consequence of the ultralow thermal conductivity, the resulting $\mathrm{ZT}$ is excellent above the first phase transition at $c a$. $460 \mathrm{~K}$, with unsubstituted bornite reaching a $\mathrm{ZT}=0.55$ at 543 $\mathrm{K}$. This is higher than the previously reported value, $\mathrm{ZT}<0.3$, for a sample prepared by conventional solid-state synthesis. ${ }^{8}$ This large difference may be related to the presence of exsolved $\mathrm{Cu}_{2-x} \mathrm{~S}$ in the conventionally prepared material, given that the temperature dependence of its Seebeck coefficient ${ }^{8}$ is similar to that obtained for $\mathrm{Cu}_{2-x} \mathrm{~S}$-containing bornite reported here (measurement 3 in Fig. 4). Although low levels of manganese substitution reduce the thermal conductivity, the power factor is also reduced. At high levels of manganese substitution, there is a slight increase in the power factor, but the thermal conductivity is also higher. Overall, all manganesesubstituted samples have a ZT comparable to that of unsubstituted bornite, when taking into account the experimental uncertainty in the measurements. The values of ZT found here at moderate temperatures, suitable for wasteheat recovery, compare favourably with those of other tellurium-free sulfides. For example, $\mathrm{Ti}_{1+x} \mathrm{~S}_{2}{ }^{2}{ }^{2} \mathrm{LaGd}_{1.03} \mathrm{~S}_{3}{ }^{28}$ or $\mathrm{Cu}_{4} \mathrm{Mo}_{6} \mathrm{~S}_{8}{ }^{29}$ exhibit $\mathrm{ZT} \geq 0.4$ but at higher temperatures, while for the recently reported $\mathrm{Co}_{3} \mathrm{Sn}_{2-x} \ln _{\mathrm{x}} \mathrm{S}_{2}$, the maximum $\mathrm{ZT}$ value is 0.32 at $673 \mathrm{~K}^{30}$

\section{Conclusions}

We have demonstrated that bornite can be synthesised by ball milling of elemental stoichiometric mixtures followed by hot pressing. This synthetic methodology offers many advantages over high-temperature solid-state reactions, as it is faster, safer and readily scalable. In the case of bornite, ball milling leads to a material with a superior thermoelectric performance ( $\mathrm{ZT}=0.55$ at $543 \mathrm{~K}$ ) when compared to conventionally prepared samples. Sulphur loss above $600 \mathrm{~K}$ leads to degradation of the thermoelectric properties of bornite at high temperatures. However, the material is stable below $580 \mathrm{~K}$, when repeatedly measured over a period of 10 weeks. We have also shown that the solubility limit of manganese in bornite is $x \approx 0.1$, but manganese substitution does not result in a substantial improvement in ZT. Owing to the high Seebeck coefficient and the ultralow thermal conductivity of this material, there is significant scope for further improvement of the thermoelectric figure of merit through the identification of suitable dopants.

\section{Acknowledgements}

The authors would like to thank the University of Reading for financial support for G.G., and for access to the Chemical Analysis Facility for powder X-ray diffraction, SEM and TGA/DSC measurements.

\section{Notes and references}

1. D.M. Rowe, Thermoelectrics Handbook: Macro to Nano, Ed. D.M. Rowe, CRC Press, Boca Raton, FL, 2006, Chapter 1.

2. M. Beaumale, T. Barbier, Y. Breard, G. Guelou, A. V. Powell, P. Vaqueiro and E. Guilmeau, Acta Mater., 2014, 78, 86.

3. X. Lu, D. T. Morelli, Y. Xia, F. Zhou, V. Ozolins, H. Chi, X. Zhou and C. Uher, Adv. Energy Mater., 2013, 3, 342.

4. T. Barbier, P. Lemoine, S. Gascoin, O. I. Lebedev, A. Kaltzoglou, P. Vaqueiro, A. V. Powell, R. I. Smith and E. Guilmeau, J. Alloys Compd., 2015, 634, 253.

5. X. Lu, D. T. Morelli, Y. Xia and V. Ozolins, Chem. Mater., 2015, 27, 408. 
6. X. Fan, E. D. Case, X. Lu and D. T. Morelli, J. Mater. Sci., 2013, $48,7540$.

7. X. Lu and D. T. Morelli, Phys Chem Chem Phys., 2013, 15, 5762.

8. P. Qiu, T. Zhang, Y. Qiu, X. Shi and L. Chen, Energy Environ. Sci., 2014, 7, 4000.

9. A. J. Frueh, Am. Mineral., 1950, 35, 185.

10. N. Morimoto and G. Kullerud, Am. Mineral., 1961, 46, 1270.

11. B. A. Grguric, A. Putnis and R. J. Harrison, Am. Mineral., 1998, 83, 1231.

12. K. Koto and N. Morimoto, Acta Cryst. B, 1975, 31, 2268.

13. Y Ding, D. R. Veblen, C. T. Prewitt, Am. Mineral., 2005, 90, 1256.

14. Y. Kanazawa, K. Koto and N. Morimoto, Can. Mineral., 1978, 16, 397.

15. Y. Ding, D. R. Veblen, C. T. Prewitt, Am. Mineral., 2005, 90, 1265.

16. B. A. Grguric and A. Putnis, Can. Mineral., 1998, 36, 215.

17. Y. Xu and M. A. A. Schoonen, Am. Mineral., 2000, 85, 543.

18. A. M. Wiltrout, N. J. Freymeyer, T. Machani, D. P. Rossi and K. E. Plass, J. Mater. Chem., 2011, 21, 19286.

19. P. Kumar, M. Gusain, P. S. Kumar, S. Uma and R. Nagarajan, RSC Adv., 2014, 4, 52633.

20. A. C. Larson and R. B. von Dreele "General Structure Analysis System (GSAS)", Los Alamos National Laboratory Report LAUR, 2004, 86-748.

21. R. D. Cowan, J. Appl. Phys., 1963, 34, 926.

22. R. Brett and R. A. Yund, Am. Mineral., 1964, 49, 1084.

23. M. G. Townsend, J. R. Gosselin, R. J. Tremblay, L. G. Ripley, D. W. Carson and W. B. Muir, J. Phys. Chem. Solids, 1977, 38, 1153.

24 H. Liu, X. Shi, F. Xu, L. Zhang, W. Zhang, L. Chen, Q. Li, C. Uher, T. Day and G. J. Snyder, Nature Mater., 2012, 11, 422.

25 L. D. Zhao, S.-H. Lo, Y. Zhang, H. Sun, G. Tan, C. Uher, C. Wolverton, V. P. Dravid and M. G. Kanatzidis, Nature, 2014, 508, 373 .

26. M. L. V. Ramires, C. A. Nieto de Castro, Y. Nagasaka, A Nagashima, M. J. Assael and W. A. Wakeham, J. Phys. Chem. Ref. Data, 1995, 24, 1377.

27. Y. He, T. Day, T. Zhang, H. Liu, X. Shi, L. Chen and G. J. Snyder, Adv. Mater., 2014, 26, 3974.

28. M. Ohta, S. Hirai and T. Kuzuya, J. Electron. Mater., 2011, 40, 537.

29. M. Ohta, H. Obara and A. Yamamoto, Mater. Trans., 2009, 50, 2129.

30. J. Corps, P. Vaqueiro, A. Aziz, R. Grau-Crespo, W. Kockelmann, J.-C. Jumas and A. V. Powell, Chem. Mater., 2015, 27, 3946. 